\title{
Inclusive Language as a Pedagogical and Motivational Tool in Early Childhood Settings: Some Observations
}

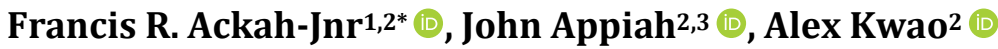 \\ ${ }^{1}$ Griffith College, Griffith University, Brisbane, Australia \\ ${ }^{2}$ Department of Basic Education, University of Cape Coast, Cape Coast, Ghana \\ ${ }^{3}$ College of Education, Department of EFLT, Auburn University, Alabama, USA \\ Email: *fr.ackahjnr@yahoo.com
}

How to cite this paper: Ackah-Jnr, F. R., Appiah, J., \& Kwao, A. (2020). Inclusive Language as a Pedagogical and Motivational Tool in Early Childhood Settings: Some Observations. Open Journal of Social Sciences, 8, 176-184.

https://doi.org/10.4236/jss.2020.89012

Received: August 17, 2020

Accepted: September 14, 2020

Published: September 17, 2020

Copyright $\odot 2020$ by author(s) and Scientific Research Publishing Inc. This work is licensed under the Creative Commons Attribution International License (CC BY 4.0).

http://creativecommons.org/licenses/by/4.0/

\begin{abstract}
Inclusive language is essential for fostering inclusiveness, belongingness, and the valuing of children in early childhood education. In early childhood settings, inclusive language is used not only to effectively communicate instruction but also provide genuine expectations and hope for all children. However, teachers' use of non-inclusive language can serve as a disincentive, minimising how children openly learn and collaborate with peers and teachers in schools. Analysing a teacher's language use from an observational study in an early childhood classroom through a creative content analytical approach, this study reveals that teachers' non-inclusive language use impact negatively on children's learning, socialisation, emotional wellbeing, and motivation to learn. We identified effective training and professional development as an important vehicle to enhance and equip teachers with knowledge and skills of using inclusive language, particularly as both a pedagogical and motivational tool in early childhood education. The study recommends that teachers should be made aware of the importance of using inclusive language and its associated benefits for educating children rather than the use of non-inclusive language. Some practical implications for using inclusive language are also provided.
\end{abstract}

\section{Keywords}

Inclusive Language, Pedagogy, Motivation, Non-Inclusive Language, Learning, Early Childhood Education

\section{Introduction: Reimagining the Essentiality of Inclusive Language in Early Childhood Settings}

In early childhood education classrooms and settings, inclusive language is es- 
sential for fostering inclusion, belonging, and acceptance. Effective inclusive language use is instrumental in valuing and appreciating all children. It is thus essential for fostering communication and inclusive cultures in classrooms. Teachers' use of non-inclusive language however can hinder children's learning and socialisation, culminating in their inability and unwillingness, or hesitancy to openly collaborate and learn with their peers and teachers in classrooms and schools. The early childhood setting provides important avenues for teachers to give hope and scaffold children so that they can have the opportunity and space to grow and develop, learn and socialise in order to reach their potential (Ackah-Jnr, 2020), so teachers' language in educating these children matter. Teachers' language can thus be sources of inclusion or exclusion in schools. Because language is key to success in life and education, the National Teachers' Standards for Ghana (2018) recognises the need for teachers to use inclusive strategies and communicate in language that engages all learners.

The central argument of our synoptic paper is that teachers can use inclusive language (IL) pedagogically and motivationally to support and enhance children's learning, socialisation and emotional wellbeing. The paper critically analyses a teacher's language use from an observational study of an early childhood classroom and provides insights on how non-inclusive language impact children's learning, socialisation, and motivation to learn. This teacher is carefully selected through convenience sampling strategy as a case relevant to map language use in an early childhood setting. The key extract for the analysis, interpretation and conclusion of this study is captured as follows:

A kindergarten class two (KG2) teacher made this announcement to her class just before morning break. "Hello class! You can all go out for break except John who has not been able to write the numeral 3. He will forfeit his break. If you come back from break and he has still not been able to write it, you will all hoot at him... I do not know what is wrong with him! Abon'! Everyday... This is an easy task." (Classic extract from an observation of a rural school teacher in Ghana, Maame $\mathrm{Aka}^{2}$; name used as pseudonym).

\section{Explaining Some Key Concepts}

To enhance our understanding, three key concepts, inclusive language as a pedagogical tool, inclusive language as a motivational tool and early childhood classroom are defined. Inclusive language as a pedagogical tool denotes language that recognises individual differences, fosters self-esteem and supports teaching and learning in the classroom. Such language allows children to "readily" understand and apply concepts in all subject areas. As a motivational tool, inclusive language provides constructive feedback and scaffolds children in their learning ${ }^{1}$ Abon literally means that one is not intelligent, but it is offensive as it is laden with other meanings.

${ }^{2}$ Maame Aka is a female rural teacher with over 10 years teaching experience in early childhood education. 
as they recognise and develop their potential. Such language should sound positive even when it is used as corrective measures and create opportunity for performance, while ensuring that teacher-pupil relationship is kept intact in the teaching and learning environment. We consider an early childhood classroom as a setting where teachers should provide diverse opportunities and scaffold children's learning, socialisation and emotional wellbeing for developing their potential.

\section{Meaning-Making Process of an Early Childhood Teacher's Language Use}

Our observations from an early childhood setting and a teacher's language use are based on a textual, content and reflective analytic approach, that is novel and creative, focusing on a classic extract, which is aimed at gaining understanding of how teachers make sense and communicate teaching and learning experiences to children. We focused on the spoken language of teacher Maame Aka to draw meaningful cues to interpret a teacher's communication in an early childhood classroom. Theoretically and methodologically, we were mainly interested in meaning-making and the effects associated with the teachers' words, regarding children's learning. The chosen text is selective, but we believe it is embedded with specific messages and message characteristics of realities in school experiences, from which these key research questions can be asked and answered: How inclusive is teachers' language use in early childhood settings? How does non-inclusive language impact children in early childhood settings? Why do teachers use non-inclusive language? In what ways can teachers be supported to use inclusive language to enhance early childhood teaching and learning? By analysing the teacher's extract, we gathered insights about language use that have implications for inclusive education, a commitment Ghana and other countries have made.

\section{Observations and Insights from an Early Childhood Teacher's Language Use}

This classic extract scenario from a rural school about language use is not unique to this Ghanaian early childhood teacher, Maame Aka, but a characterisation of many other teachers in early childhood classrooms and schools in many developing countries, including Ghana. The language used or choice of words in communicating the teacher's intention [(al) practice] in this early childhood setting at the outset might seemingly not be inappropriate, but it is intended to urge John to put in extra effort to finish the numeracy task as his peers did. For the early childhood teacher, the implicit motive is to serve a motivational purpose to enhance John's academic performance in numeracy. However, the language used has negative connotations as it is derogatory, demeaning, and discriminatory, and at best threatening and exclusive. In another breath, such language may impact negatively on John's self-esteem, self-expression, and self- 
identity. Overall, the scenario creates two possible outcomes in this early childhood setting, like others, which are all negative:

In the first instance, if John is able to complete the task, the teacher's action might have served as an extrinsic incentive that yielded a positive outcome or performance. Whilst this practice is somewhat motivational, it is contingent on or encrusted with a condition (fear to forfeit break or being hooted at), so its effect could be immediate but short-term. Here, teacher Maame Aka could have adopted an appropriate approach to "motivate" John for sustained performance or learning without necessarily making his challenge of writing the numeral 3 overtly known to the whole class or to attract an induced gaze from his peers. This practice usually results in name-calling (e.g. abon, that is you are not intelligent at all as used by the teacher), ridicule, teasing and other self-fulfilled prophecies. It is stigmatising and demotivating. Again, in a situation where John is unable to finish the numeracy task due to a peculiar developmental challenge, misunderstanding of the concept taught, absence of individualisation of instruction and task, or home factors such as bereavement, family conflict and child abuse which the teacher has not investigated or identified before making the announcement to the whole class, this action will negatively impact John emotionally, socially, or academically, or further aggravate his feelings of low self-esteem, self-worth and belief, if any. It is evident that the teacher in making this announcement to the class did not show respect to John or failed to recognise the concept of individual differences in learning and cognitive development and performance. Although John is in KG2, he must be treated with respect where both his strengths and weaknesses are appreciated and recognised. Thus, teachers like Maame Aka should promote respectful behaviours in early childhood settings. Using respectful, appreciative and inclusive language has the potential to facilitate communication, engagement, and participation in the learning and social routines. Such inclusive language could also enhance struggling students' self-esteem and possibly eliminate their feelings of inferiority complex.

In the second instance (from the scenario), for other children in the class who might not be emotionally strong or are not used to such open attention-seeking or shaming practice, just upon hearing the teacher's announcement could result in making them cry, panic, frighten and restless, or becoming stressed. The probable outcome for these children would be their inability to finish the task, but the teacher would be unsympathetic and keep her promise of allowing the children to be hooted at. For many such children like John who encounter this situation in early childhood settings, their confidence, self-esteem, and morale could be dampened. They could perceive school experiences as unhealthy and unfriendly, leading to feelings of frustration, anxiety, or failure. This practice has the propensity to affect children's academic development and learning which could culminate in periodic absenteeism and school dropout. These are some of the everyday conscious or unconscious characterisations and effects of many teachers' practices in early childhood classrooms, which hitherto should be more inclusive, fair, and welcoming for all children and their learning differences. In 
the $21^{\text {st }}$ century, early childhood settings should become more inclusive where diversity is valued, and everyone's contribution, performance and effort are recognised and scaffolded. Therefore, the language of teachers should be appreciative so that this might not negatively impact or lead to subtleties in the learning and social experiences of children.

Following the classroom scenario, teachers' use of language, whether verbal or non-verbal, is considered critical for instruction, learning and socialisation in classrooms. Language is one of the key modes of communication for putting across our developmental thoughts and information. It is the lifeblood of dynamic and progressive societies, having educational, social, economic, and scientific benefits that cannot be underestimated (Baglieri \& Shapiro, 2012). Language is used verbally, symbolically, and visually to transit information and shared ideas among individuals, and in relationships, it is that which bridges and binds people together. Effective language use in typical early childhood settings should thus be developmentally sensitive or age appropriate (Bredekamp, 2011). Therefore, teachers' choice of language should foster children's understanding of concepts and promote healthy teacher-pupil and pupil-pupil relationships in classrooms. It is in the light of these that teachers' use of inclusive language in early childhood settings is important.

\section{What Is This Inclusive Language? What Is Its Significance in Early Childhood Education?}

From the content analysis of the classroom scenario, an inclusive language includes children in the learning and social activities and routines of early childhood settings rather than excludes them. Inclusive language, also called nondiscriminatory language, is a language that is sensitive to and respectful of learners. The Department of Education (2019), Tasmanian Government Inclusive Language Guidelines, defines inclusive language as:

language that is free from words, phrases or tones that reflect prejudiced, stereotyped, or discriminatory views of particular people or groups. It is also language that doesn't deliberately or inadvertently exclude people from being seen as part of a group (p. 3).

In this paper, we further conceive inclusive language as when teachers use appreciative words or say positive things about learners so that they feel valued and accepted in early childhood settings. We claim also that inclusive language is a powerful vehicle for communication and instruction, serving as a pedagogical and motivational tool for teaching and learning of all learners. It is thus important teachers ensure their classroom instruction is devoid of language of prejudice, divisiveness, stereotype, and discrimination. Language that is inclusive reflects us and our world; hence, teachers' use of patronising and shaming language creates labelling in schools (Baglieri \& Shapiro, 2012; Foreman \& Arthur-Kelly, 2014). Teachers therefore need to be conscious and guard against all forms of discriminatory language, intonation, and innuendos. With the growing 
call for inclusion, equity, and equality in education (Ackah-Jnr, 2020; Ainscow, 2020; Baglieri \& Shapiro, 2012; Foreman \& Arthur-Kelly, 2014) teachers must embrace and promote the use of inclusive and unifying language. Effective use of inclusive language in classrooms will signify teachers' preparedness, acceptance, and support for eliminating exclusionary practices.

Based on the class scenario, we argue that early childhood teachers' effective use of inclusive language in classrooms benefits all children in several ways including their social, emotional, moral, and cognitive/intellectual development (Bredekamp, 2011). Children that feel appreciated, respected and recognised as members of their class, develop the confidence and inner motivation to openly learn and interact with their teachers and peers. They assume a sense of pride to learn that fosters cognitive development. Socially, children can interact with their peers or engage in play and other social activities. Through this social exchange, they learn from each other. Emotionally, children do not feel depressed or isolated from their friends and teachers when respectful language is used. This feeling puts them in a state of psychological balance, enhancing their self-esteem. Morally, when children are in classrooms where they are valued and are not discriminated against, they can make the right choices. When these developmental domains of children are enhanced, they are motivated to learn and socialise in the classroom setting.

\section{Why Non-Inclusive Language and What Can Be Done?}

The scenario analysis laid bare some of the detrimental and stigmatising effects of using non-inclusive language in early childhood classrooms and settings. It is worrying to note that many teachers, including teacher Maame Aka, as exemplified in Ghana, are unaware of the need to use inclusive language and the benefits thereof. Such teachers may lack requisite training in inclusive education and related issues. In most cases, these teachers are intolerant and impatient with struggling students and resort to using disrespectful, abusive language and other non-inclusive languages in classrooms. And this practice is prevalent in areas and schools which prohibit the use of corporal punishment or where teachers feel frustrated due to excessive teacher workload or threats of large class size demands (Ackah-Jnr \& Udah, In Press). Other teachers' language use reflects their ignorance and negative dispositions and attitudes to inclusive education. What then can be done to help teachers to foster inclusive language use in early childhood settings?

Based on the negative effects and implications inherent in the use of inappropriate and non-inclusive language on children's learning, socialisation and emotional wellbeing in early childhood settings, as exemplified in the class scenario, it is important for issues of inclusive language to be promoted to help teachers create enabling classroom environment to support learning. It is clear that language essentially has a powerful influence on the way we think and act as teachers and educators, and this is true especially for those teachers perceive or are 
perceived to be different (Foreman \& Arthur-Kelly, 2014) intellectually or behaviourally in schools. Therefore, during teacher education or professional development programs, inclusive language should form part of the curriculum and treated as a pedagogical tool to ensure that teachers are well educated and sensitised about its effective use for instruction and motivation in schools. Early childhood education requires competent teachers who are: fully prepared to teach the school curricula and use a learner-centred pedagogy and an inclusive approach (National Teacher Education Curriculum Framework [NTECF], 2018). Again, inclusive language must be used as a positive culturally responsive pedagogy that recognises learners with differing academic backgrounds and levels of competencies. Teachers need to continually fine-tune and enhance their teaching skills and knowledge of inclusive education in order to enact appropriate practices to limit the frontiers of exclusion.

In conclusion, John's teacher's language, like many other teachers, is rooted in the medical model of disability that focuses on the inability or problem of John, rather than the perceived barriers imposed by the environment that impacts John's learning. It is self-fulfilling, which does not recognise John's ability or what he can do when appropriately scaffolded. What then could teacher Maame Aka, like other teachers, do to support John? There is the need for teachers to change their use of languages of disablement to one (inclusive language) that projects the enhancement, enablement, and empowerment, as well as motivation of children in the learning and social spaces in early childhood education. Ideally, teacher Maame Aka could have used inclusive language as a motivational tool and pedagogy of hope to foster John's learning:

Hello class! You can go out for break. John will come later. I am making time to scaffold him to learn how to write the numeral 3 as you have done. During the day or week, John would be able to write it. I will help him because I know he can. We all learn at a different pace, so we must continue to help each other in class (Authors' refined extract of inclusive language use).

\section{What Does Teachers' Non-Inclusive Language Use Tell Us? What Are the Practical Implications of Using Inclusive Language?}

Essentially, teacher Maame Aka's non-inclusive language has detrimental effects on John's learning, socialisation and emotional wellbeing and motivation to learn. This tells us that some teachers are unaware of the negative impact of non-inclusive language use on children's development. It signals the call for advocacy and use of inclusive language in early childhood classroom settings. The refined extract exemplifies an inclusive language that John's teacher, like other teachers could use in schools and early childhood classrooms, which is necessary for promoting learning, socialisation and communication cultures or inclusive cultures. Some practical implications of using such an inclusive language are 
drawn and discussed succinctly:

1) Effective inclusive language needs to be used to foster active and collaborative learning. When such language is used children are able to openly participate in class instruction and activities without the fear of being abused, harassed, or mocked by their teachers or peers. Children are also free to float ideas, answers and make contribution in class.

2) Effective inclusive language like the refined extract can potentially ease the power distance and relations between students and teachers. Such inclusive language can create friendly and lively environment where students and teachers interact and socialise in respectfully and appropriate ways. Therefore, teachers should be respectful and mindful of their choice of words in classrooms. Using respectful inclusive language further lessens the tension that characterises many classrooms.

3) Teachers should consider individual differences in the learning and socialisation process of early childhood education. Due cognisance needs to be given to the diverse abilities of children, and avoidance of use of language that suggests disablement.

4) Consideration needs to be focused on identifying the implicit and explicit school and home factors that impact children's learning and socialisation.

5) Inclusive language should be used as an effective pedagogical tool that individualises and scaffold teaching and learning, as well as a motivational strategy to give hope to children, especially those with learning challenges rather than using it as a deterring mechanism to create despair in early childhood setting.

6) Ineffective inclusive language use is a complete dichotomy between classroom policy and practice since opportunity for the child to learn rather becomes a hindrance. This requires teacher motivation.

7) Non-inclusive language use creates poor communication link between the teacher and the child regarding content knowledge and pedagogical knowledge. This is because of inadequate spaces for the child's learning process. In this case, equal opportunity in classroom is relevant.

8) Inappropriate use of language is a deviation from the ethical values, attitudes, and knowledge standards of professional teachers. Thus, teachers must have a balanced personality and use refined or appropriate teaching methods that are saturated with inclusive language.

9) Every child in a class has naturally endowed talent. Therefore, it is the duty of the class teacher to help children make exploits their potentialities. This can nurture and develop multiple intelligences of children in the early childhood schools and classrooms.

\section{Conflicts of Interest}

The authors declare no conflicts of interest regarding the publication of this paper.

\section{References}

Ackah-Jnr, F. R. (2020). Inclusive Education, a Best Practice, Policy and Provision in 
Education Systems and Schools: The Rationale and Critique. European Journal of Education Studies, 6, 171-183.

Ackah-Jnr, F. R., \& Udah, H. (In Press). Inclusion in Early Childhood Education. The Interplay and Impact of Exclusion, Teacher Qualities and Professional Development.

Ainscow, M. (2020). Promoting Inclusion and Equity in Education: Lessons from International Experiences. Nordic Journal of Studies in Educational Policy, 6, 7-16.

https://doi.org/10.1080/20020317.2020.1729587

Baglieri, S., \& Shapiro, A. (2012). Disability Studies and the Inclusive Classroom: Critical Practices for Creating Least Restrictive Attitudes. New York, NY: Routledge. https://doi.org/10.4324/9780203837399

Bredekamp, S. (2011). Effective Practices in Early Childhood Education: Building a Foundation. Upper Saddle River, New Jersey: Pearson Education Inc.

Department of Education (2019). Inclusive Language Guidelines. Tasmanian: Tasmanian Government.

Foreman, P., \& Arthur-Kelly, M. (2014). Inclusion in Action (4th ed.). South Melbourne, Victoria: Cengage Learning Australia.

National Teacher Education Curriculum Framework (NTECF) (2018). The Essential Elements of Initial Teacher Education. Ghana: Ministry of Education.

National Teachers' Standards for Ghana (2018). Guidelines. Ghana: Ministry of Education. 